the two bending vibration frequencies. The average percentage error between calculated and observed frequencies for other $A B_{3}$ planar molecules and ions is: $\mathrm{BF}_{3}: 0.1 ; \mathrm{BCl}_{3}: 1.45 ; \mathrm{CO}_{3}^{=}: 0.2 ; \mathrm{NO}_{3}^{-}: 3.4$; $\mathrm{SO}_{3}: 0.55$. There seems no doubt, therefore, that the orbital valency force field provides a much more satisfactory force field than the simple valency force field which requires two unrelated bending constants for planar $A B_{3}$ molecules. We have also found that the orbital valency force field is better than the simple valency force field (both being combined with repulsion between the non-bonded atoms) for "eighttetrahalides' like $\mathrm{CCl}_{4}$ and 'four-ions' like $\mathrm{SO}_{4}{ }^{6}{ }^{6}$. We are proceeding to apply the orbital valency force field to other molecules.

\section{F. Heath}

J. W. LINNETT

Inorganic Chemistry Laboratory,

Oxfurd.

Dec. 19.

' Urey and Bradley, Phys. Rev., 38, 1969 (1931). Thompson and Linnett, J. Chem. Soc., 1392 (1937). Linnett. $J$. Chem. Phys. 8, 95 (1940). Thorndike, Wells and Wilson, J. Chem. Phys., 15, 157 (1947). Coulson, Duchesne and Manneback, Nature, 160 794 (1947). Heath and Linnett, Trans. Farad. Soc., in the press. 'Heath and Linnett, Trans. Farad. Soc. (in the press). We have Wilson for PCl, type molecules, $J$. Chem. Phys., 2, 620 (1934).

- Pauling, J. Amer. Chem. Soc., 53, 1367 (1931).

- Lennard-Jones, Proc. Roy. Soc., A, 106, 463 (1924).

- Anderson, Lasettre and Yost, J. Chem. Phys., 4, 703 (1936).

- Heath and Linnett, Trans. Farad. Soc. (in the press).

\section{Band Spectrum of Aluminium Bromide}

THE ${ }^{1} I I-{ }^{2} \Sigma$ system of AlBr near $\lambda 2790$ has been photographed in emission with high dispersion $(0.6 \mathrm{~A} . / \mathrm{mm}$.). Measurements of the $Q$ heads have verified Howell's analysis'. Howell was, however, not able to make any definite observations on the isotope effect of the $Q$ heads. Some of his $Q$ heads, therefore, refer to the molecule $\mathrm{AlBr}^{79}$, others to the molecule $\mathrm{AlBr}^{81}$. On account of this, a new $Q$ head formula has been calculated. Thus the band-origins of the molecule $\mathrm{AlBr}^{79}$ can be represented by the formula :

$v=35879 \cdot 5+297 \cdot 2\left(v^{\prime}+\frac{1}{2}\right)-6.40\left(v^{\prime}+\frac{1}{2}\right)^{2}-$

$0.527\left(v^{\prime}+\frac{1}{2}\right)^{3}-378 \cdot 0\left(v^{\prime \prime}+\frac{1}{2}\right)+1.28\left(v^{\prime \prime}+\frac{1}{2}\right)^{2}$.

The rotational structure of the $0,1,1,0,1,1,1,2$, $1,3,2,1,2,2,2,3$ and 2,4 bands has been analysed. On account of the close structure, the bands were not resolved up to the heads. The analysis gives the following values for the band-constants:

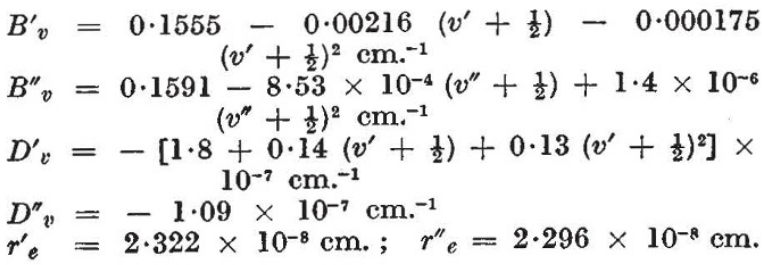

The observed rotational isotope separations agree well with those calculated, but the approximate formula $\Delta v_{r}=\left(1-\rho^{2}\right) \nu_{r}$ cannot be used.

The calculated values of the separations of $R$ and $Q$ heads agree well with those observed.

The frequency $\omega_{e}$ has been calculated from Guggenheimer's formula ${ }^{2}$. This gives in the case of AlBr, $\omega_{e}=370 \cdot 3$, in rather good agreement with the observed value $\omega_{e}=378 \cdot 0$.
A more detailed account of the analysis will be published in the Ark. f. Mat. Astr. o. Fys.

Physical Institute, Carl Gustav Jennergren

University of Stockholm. Sept. 30.

${ }^{2}$ Howell, Proc. Roy. Soc., A, 148, 696 (1935).

${ }^{2}$ Guggenheimer, Proc. Phys. Soc., 58, 456 (1946).

\section{Comparison of Metallographic and X-Ray Measurements of Retained Austenite}

THE martensite reaction in steels has been studied by microscopic examination of polished and etched samples after the samples have been tempered for short periods of time. One etching reagent which has been used is a solution of 6 per cent nitric acid in alcohol, which is called 6 per cent nital. This etchant stains the martensite grey or black and leaves the austenite white.

In quantitative studies of the amount of austenite which was retained after quenching to room temperature, this etchant appeared to obscure some of the austenite when the specimens were quenched from austenitizing temperatures below $1750^{\circ} \mathrm{F}$. $\left(954^{\circ} \mathrm{C}\right.$. $)$. In steels exhibiting temper brittleness, Cohen, Hurlich and Johnson have found that the addition of a wetting reagent called 'Zephiran Chloride' to a modified picric acid etch reveals a precipitate not shown by other etching reagents'. ('Zephiran Chloride' is a trade-mark of Winthrop Chemical Company, Inc., indicating its brand of a mixture of high molecular alkyl-dimethyl-benzyl-ammonium chlorides, the descriptive name of which is benzyltrialkonium chloride, marketed as an aqueous solution containing 12.8 per cent 'Zephiran Chloride'.) Therefore, 1 per cent 'Zephiran Chloride' was added to nital in an attempt to increase the sensitivity of the nital. Although 6 per cent nital is a better etchant than 4 per cent nital for steels containing small amounts of austenite, it is necessary to reduce the amount of nitric acid in the etch containing 'Zephiran Chloride' to 4 per cent because the 'Zephiran Chloride' increased the speed of etching.

COMPARISON OF METALLOGRAPHIO AND X-RAT MEASUREMBNTS OF AMOUNT OF RETAXNED AUSTENITE AT ROOM TEMPERATURE $\left(68^{\circ} \mathrm{F}, 2^{\circ} \mathrm{C}\right.$.)

\begin{tabular}{|c|c|c|c|}
\hline & Metallographic & measurements & X-ray \\
\hline $\begin{array}{c}\text { Austenitizing } \\
\text { temperature }\end{array}$ & $\begin{array}{c}\text { Standard etch } \\
6 \% \text { nital }\end{array}$ & $\begin{array}{l}\text { (4\% nital and } \\
1 \% \text { 'Zephiran }\end{array}$ & ments \\
\hline
\end{tabular}

$\begin{array}{lcrr}1450^{\circ} \mathrm{F} .\left(788^{\circ} \mathrm{C} .\right) & 0 & 2 \cdot 0 \pm 1 \cdot 0 \% & 3 \cdot 1 \pm 0 \cdot 2 \% \\ 1550^{\circ} \mathrm{F} .\left(843^{\circ} \mathrm{C} .\right) & 0 & 6 \cdot 0 \pm 1 \cdot 0 \% & 7 \cdot 0 \pm 0.4 \% \\ 1650^{\circ} \mathrm{F} .\left(899^{\circ} \mathrm{C} .\right) & 3 \cdot 0 \pm 3 & 14 \cdot 0 \pm 1.0 \% & 14 \cdot 0 \pm 0.8 \% \\ 1750^{\circ} \mathrm{F} .\left(954^{\circ} \mathrm{C} .\right) & 17 \cdot 0 \pm 1 & 20 \cdot 0 \pm 1.0 \% & 20 \cdot 0 \pm 1 \cdot 0 \%\end{array}$

Critical measurements were made on a $1 \cdot 1$ per cent carbon, 1.4 per cent chromium steel, quenched into oil at $68^{\circ} \mathrm{F}$. $\left(20^{\circ} \mathrm{C}\right.$.) from a series of austenitizing temperatures listed in the accompanying table. $\mathrm{X}$-ray measurements utilizing a new technique were made on these steels by Averbach ${ }^{2}$. Then the specimens were tempered for 10 sec. at $630^{\circ} \mathrm{F}$., and were polished and etched. Quantitative measurements were made metallographically of the amount of retained austenite using a Hurlbut counter, described by Howard and Cohen ${ }^{3}$. The metallographic measure. ments with the improved etch wore practically identical with the X-ray measurements, although the reproducibility of the $X$.ray results was better than that of the metallographic results, and the X-ray measurements revealed slightly more austenite than 